BAND, R. N. (1959). J. gen. Microbiol. 21, 80-95

\title{
Nutritional and Related Biological Studies on the Free-Living Soil Amoeba, Hartmannella rhysodes
}

\author{
By R. N. BAND* \\ Department of Zoology, University of California, Berkeley, California, U.S.A.
}

SUMMARY: Hartmannella rhysodes Singh was cultivated under axenic conditions at $25-30^{\circ}$ in a buffered physiological salt solution containing $1 \%(\mathrm{w} / \mathrm{v})$ proteose peptone and a suitable additional carbon source. Optimal growth and maximum cyst formation were obtained aerobically under constant agitation in vessels coated with silicone. The addition of a thickening agent did not improve growth. No cysts were formed at low oxygen tensions. This may reflect a fundamental metabolic block in cyst formation. Growth curves were obtained with a variety of carbon sources : glucose, maltose and mannose supported optimal growth; lactose supported unusual growth which resembled diauxie. By testing for reducing sugars, no utilization of glucose was detected. A specific chemical test for glucose revealed that glucose was utilized during growth and by resting suspensions. Through the use of uniformly labelled ${ }^{14} \mathrm{C}$ glucose, it was possible to demonstrate that glucose was assimilated and also used as an energy source during growth. The osmotic concentration required for optimal growth was in itself not optimal when the total osmotic pressure was kept constant and the concentration of utilizable carbon sources was decreased.

Hartmannella rhysodes Singh is a small naked amoeba which forms nonreproductive cysts; it was isolated from soil and described by Singh (1952). It is placed in the family Hartmannellidae, class Sarcodina.

Physiological studies on small soil amoebae have yielded contradictory results. A requirement for an added carbon source, in addition to the basal medium, was described for a species of Acanthamoeba (Neff, 1957) and for Mayorella palestinensis (Reich, 1935). Evidence will be presented in this paper that this is also true for Hartmannella rhysodes and $A$. castellanii. However, neither Reich $(1948,1955)$ by respirometry nor Neff, Neff \& Taylor (1958) by direct chemical analysis were able to show the use of glucose during growth. Cailleau $(1933 a, b, 1934)$ was unable to demonstrate either the need for, or utilization of, an added carbon source by $A$. castellanii. Operating within the restrictions imposed by the lack of a completely defined medium, the objectives of the present study were: (1) to study the utilization of different carbon sources, as measured by the growth response of $H$. rhysodes; $(2)$ to examine by direct chemical analysis whether glucose was utilized as a carbon source; (3) to investigate some aspects of the general physiology of $H$. rhysodes as related to its life cycle.

\footnotetext{
* Present address : Department of Biology, Amherst College, Amherst, Massachusetts, U.S.A.
} 


\section{METHODS}

Organism. Hartmannella rhysodes Singh and Acanthamoeba castellanii (Douglas) Volkonsky were obtained from Dr William Balamuth(Department of Zoology, University of California). The strains originated in the laboratories of Dr B. N. Singh and Dr A. Lwoff, respectively. H. rhysodes was the organism of primary interest; $A$. castellanii was used only in one experiment to demonstrate its growth response to glucose.

\section{Culture procedures}

Culture medium. The fluid culture medium used routinely and referred to as Amoeba Medium was modified from Neff's (1957) amoeba medium. The medium contained: $120 \mathrm{mg}$. $\mathrm{NaCl} ; 3 \mathrm{mg} . \mathrm{MgCl}_{2} \cdot 6 \mathrm{H}_{2} \mathrm{O} ; 3 \mathrm{mg} . \mathrm{CaCl}_{2} ; 3 \mathrm{mg}$. $\mathrm{FeSO}_{4} ; 142 \mathrm{mg} . \mathrm{Na}_{2} \mathrm{HPO}_{4} ; 136 \mathrm{mg}$. $\mathrm{KH}_{2} \mathrm{PO}_{4} ; 10 \mathrm{~g}$. Proteose Peptone (Difco); $18 \mathrm{~g}$. glucose; water to $1 \mathrm{l}$; ; final $\mathrm{pH}$ value $6 \cdot 8$.

In order to test the ability of different carbon sources to support the growth of Hartmannella rhysodes, the concentration of glucose in the Amoeba Medium was decreased to $0.0025 \mathrm{M}$. The carbon sources, as well as glucose control cultures, were then tested in this modification of the Amoeba Medium, at concentrations of $0.025,0.05$ and $0.1 \mathrm{M}$. Sucrose was added to the 0.025 and $0.05 \mathrm{M}$ concentrations to increase their molar concentrations to $0.1 \mathrm{M}$.

The amoebae were tested in sodium acetate at $\mathrm{pH}$ values of 5.5-6.5. The phosphate buffer at the concentration used had no effect on the initial $\mathrm{pH}$ value of the medium. For this reason the $\mathrm{pH}$ value was adjusted with known amounts of $0.1 \mathrm{~N}-\mathrm{HCl}$. Since the total osmotic pressure was higher than that of unmodified Amoeba Medium and differed according to the desired $\mathrm{pH}$ value, they were brought to the same osmotic concentration with $\mathrm{NaCl}$. Differences in acetate concentration were not brought to the same osmotic concentration. Parallel glucose cultures were tested in this modification of the Amoeba Medium at the $\mathrm{pH}$ values used.

Sterilization of sugars. All sugar solutions were sterilized by passage through a Millipore 'WH Microweb' membrane filter (Millipore Filter Corp.).

Manipulation of cultures. Both Hartmannella rhysodes and Acanthamoeba castellanii were isolated from their bacterial associates by migration on an agar surface. This technique was used by Oehler $(1916,1924)$ in isolating soil amoebae. Axenic fluid cultures were established by this procedure. Stock cultures were established in Amoeba Medium from a single organism, isolated by the migration technique from axenic cultures growing on solid surfaces. These cultures consisted of $50 \mathrm{ml}$. Amoeba Medium in $250 \mathrm{ml}$. Erlenmeyer flasks. They were subcultured monthly, with an inoculum of $c .0 .5 \%$ of the final yield of amoebae, and incubated statically at $30^{\circ}$. Mass cultures consisted of 200-400 ml. of Amoeba Medium in 11 . Erlenmeyer flasks. These were incubated at $27^{\circ}$ on a rotary shaker. The inocula varied from $c .10$ to $25 \%$ of the final yield of organisms. Growth experiments were carried-out with $10 \mathrm{ml}$. of Amoeba Medium in $50 \mathrm{ml}$. Erlenmeyer flasks. Inocula for growth experiments were $c .1 \%$ of the final yield of organisms in a volume of Amoeba Medium not 
exceeding $0.5 \%$ of the volume of the medium to be tested. All parallel experiments received the same inoculum in respect to size and source.

Aeration and agitation. Aeration and agitation were accomplished on a rotary shaker having a radius of $\frac{1}{4} \mathrm{in}$. at $115 \mathrm{rev} . / \mathrm{min}$. The growth vessels used under these conditions were coated with silicone (Dow Corning ' 200 Fluid', $350 \mathrm{c} . / \mathrm{s}$.) according to the manufacturer's instructions. All experiments were incubated at $27^{\circ}$ on the rotary shaker unless otherwise stated.

\section{Measurement of growth}

Turbidity, measured by a 'Spectronic 20' colorimeter (Bausch \& Lomb) at $600 \mathrm{~m} \mu$, was used to estimate the number of organisms unless otherwise stated. Optically matched test-tubes, attached at right angles to the side of the culture vessels above the level of the fluid, were used in growth experiments; percentage transmission was correlated with number of organisms both by counts and turbidity measurements performed over part of the growth cycle in parallel, and by dilution of a culture containing maximum log-growth organisms with fresh medium. To correct for concentration by evaporation, volumes were measured after growth, and the volume present at each measurement were calculated by assuming that the evaporation rate was linear. In order to minimize evaporation, the cotton-plugged culture vessels were capped with aluminium foil.

\section{Analytical procedures}

Sugar analysis. Two reducing-sugar tests were used for quantitative analysis of media: (1) the Nelson photometric adaptation of the Somogyi method (Nelson, 1944); (2) the anthrone method (Südhof, Kellner \& Schulte, 1955 a, b). A specific colorimetric test for glucose, using a preparation of glucose oxidase, supplied under the name 'Glucostat' (Worthington Biochemical Corp.), was also used.

Isotope and related procedures. Isotope experiments were carried out with uniformly labelled ${ }^{14} \mathrm{C}$ glucose furnished by $\mathrm{Dr}$ Michael Doudoroff (Department of Bacteriology, University of California). The original isotope was diluted with $\mathrm{m}$-glucose solution, and added to sterile Amoeba Medium through a Swinny filter. Samples, dried on planchets under an infra-red lamp, were counted with a thin window counter and a decimal scaler for $10 \mathrm{~min}$. intervals. Carbon dioxide was collected by isolating each experiment in an all-glass culture system, which was gassed periodically with $\mathrm{CO}_{\mathbf{2}}$-free air. The $\mathrm{CO}_{2}$ was collected in $\mathrm{CO}_{2}$-free $4 \%(\mathrm{v} / \mathrm{v}) \mathrm{NaOH}$ solution, which was made from a $40 \% \mathrm{NaOH}$ solution (sp.gr. 1.43) and $\mathrm{CO}_{2}$-free water.

Dry reight; total carbon, hydrogen and nitrogen. Total nitrogen was determined by the Kjeldahl method (Steyermark, 1951). Total carbon and hydrogen determinations were performed by the combustion method (Steyermark, 1951). Dry weights were performed either by drying at $105-110^{\circ}$ or in a desiccator over $\mathrm{P}_{2} \mathrm{O}_{5}$ at $30^{\circ}$ with a slight vacuum. 


\author{
RESULTS \\ Total nitrogen and dry weight
}

Amoebae harvested during the logarithmic phase of growth were used to determine the total nitrogen content as correlated to number of organisms. Total nitrogen determinations were performed on three separate cultures of amoebae, each in quadruplicate; glycine was used as a control. The results are presented in Table 1. The dry weight of organisms harvested during the logarithmic phase of growth was determined for washed organisms dried at 105-110 ${ }^{\circ}$. Dry weight was correlated with number of organisms. The results (see Table 1) were determined from eight samples.

Table 1. Total nitrogen and dry weight of Hartmannella rhysodes based on $10^{6}$ organisms

$\begin{array}{lcc} & \begin{array}{c}\text { Total } \\ \text { nitrogen } \\ (\mathrm{mg})\end{array} & \begin{array}{c}\text { Dry } \\ \text { weight } \\ (\mathrm{mg})\end{array} \\ \text { Mean } & \mathbf{0 \cdot 0 4 6 5} & 0 \cdot 753 \\ \text { Range } & 0 \cdot 0715-0 \cdot 037 & 0 \cdot 765-0 \cdot 741 \\ \text { S.D. } & 0.0019 & 0 \cdot 017\end{array}$

\title{
Measurement of growth by turbidity
}

The number of organisms was correlated with turbidity over part of the growth cycle. A satisfactory regression line was plotted by the method of least squares by correlating the log of number of organisms with the square root of $\% T$; this correlation is presented in Fig. 1 and was found to be valid for samples derived by dilution. Periodical direct counts of organisms of all cultures measured by turbidity fell within the confidence interval for new observations.

\section{Requirements for oxygen and surfaces}

Oxygenation. In static deep cultures $(2.5 \mathrm{~cm}$.) no cysts were observed, although round forms resembling the precystic amoebae described by Ray \& Hayes (1954) were observed. In shallow $(1 \mathrm{~cm}$.) cultures both cysts and round forms were seen. A comparison of maximum yields in deep and shallow cultures and in rotary agitated cultures is presented in Table 2. The data indicate that the growth of Hartmannella rhysodes was directly related to the degree of oxygenation and that cyst formation was inhibited at low oxygen tensions.

Surfaces. When the flasks used to grow amoebae under rotary agitation were not coated with silicone, poor or no growth was obtained. The silicone coating prevented the organisms from adhering to the surface of the vessel. The addition of sodium carboxymethyl cellulose at $0,0 \cdot 1,0.5,1 \cdot 7$ and $2.5 \%$ $(w / v)$ to stationary and agitated cultures did not improve growth. Thus the addition of a compound which forms micellar surfaces did not have any effect on growth; the amoebae do not appear to require a surface for growth and multiplication.

Anaerobiosis. Incubation in an atmosphere of hydrogen and c. $10 \%(\mathrm{v} / \mathrm{v})$ 
$\mathrm{CO}_{2}$, contained in a Brewer jar, was lethal. A few amoebae survived incubation under these conditions for short time periods (c. 24 hr.) although division and cyst formation were completely arrested.

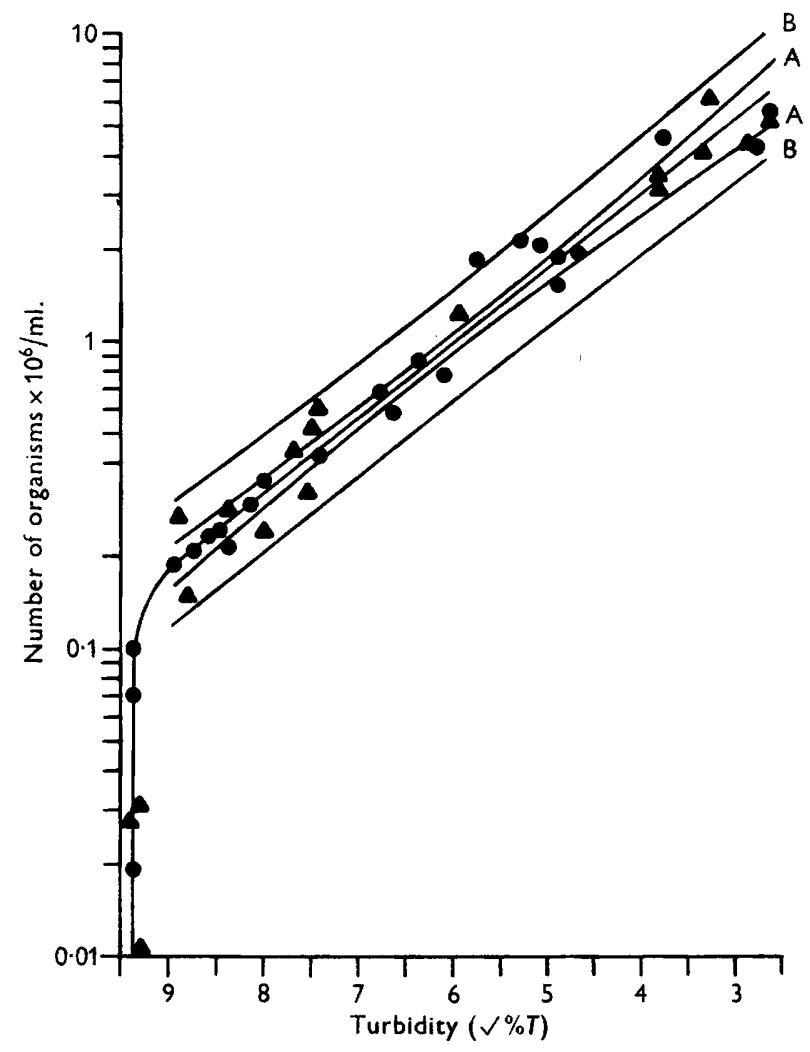

Fig. 1. Correlation of the number of organisms with turbidity. Confidence intervals are shown for the regression line (A) and for new observations (B) at the $95 \%$ level. Each point represents a sample mean. Samples were derived from parts of the growth cycle (O) from which the regression line was plotted, and by dilution of a culture in maximum log growth (A).

Table 2. A comparison of the growth of Hartmannella rhysodes under different conditions of aeration

\begin{tabular}{|c|c|c|}
\hline & $\begin{array}{c}\text { Maximum yield } \\
\left(\times 10^{6} \text { organisms } / \mathrm{mI} .\right)\end{array}$ & $\begin{array}{l}\text { Time } \\
\text { (days) }\end{array}$ \\
\hline Stationary, deep $(2.5 \mathrm{~cm})$. & $\left.\begin{array}{l}1 \cdot 13 \\
1 \cdot 77 \\
1 \cdot 19\end{array}\right\}$ & 40 \\
\hline Stationary, shallow (1 cm.) & $\left.\begin{array}{l}1 \cdot 88 \\
2 \cdot 12 \\
1 \cdot 89\end{array}\right\}$ & 26 \\
\hline Agitated by shaking $(2.5 \mathrm{~cm})$. & $\left.\begin{array}{l}3 \cdot 3 \\
4 \cdot 0\end{array}\right\}$ & 10 \\
\hline
\end{tabular}




\section{Osmotic pressure}

Osmotic pressure determination. The osmotic pressure of $1 \%(w / v)$ Proteose peptone, determined by the method of Gortner \& Harris (1914), is 0.05 osmolar; the calculated osmotic pressure for Amoeba Medium is 0.158 osmolar.

Osmotic pressure effect on growth. The effect of osmotic pressure on growth was determined by growing the amoebae in Amoeba Medium with different concentrations of glucose and sucrose in duplicate at $30^{\circ}$. Filter-sterilized sucrose did not support growth. The results (see Fig. 2) indicated that growth at all concentrations of glucose was depressed by increasing the osmotic pressure of the medium.

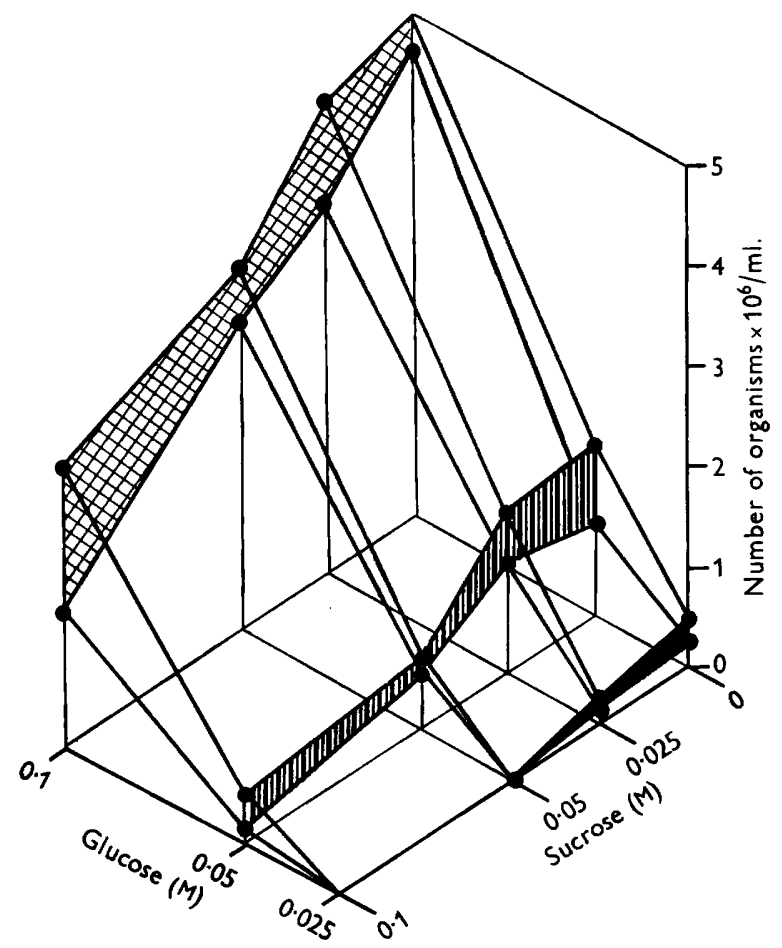

Fig. 2. Osmotic effect of sucrose on maximum yield for duplicate cultures.

\section{Growth with different carbon sources}

Known carbon sources. A comparison of the growth of Hartmannella rhysodes with various carbohydrates is shown in Table 3. Growth with sodium acetate and parallel glucose cultures is presented in Table 4.

Glucose, maltose or mannose supported the best growth. As seen in Fig. 3, growth with glucose was proportional to its concentration. The peculiar growth with lactose (Fig. 4) was not observed with any other carbon source; at all concentrations of lactose, the exponential growth phase was interrupted with a lag phase. No growth was observed with D-arabinose, D-raffinose, 
Table 3. Growth of Hartmannella rhysodes with various carbohydrates

Organisms were grown at $27^{\circ}$ on a shaker in Amoeba Medium containing the appropriate sugar in place of glucose. Data are presented as the mean of duplicate determinations. Mean generation time presented only where logarithmic growth is evident. Growth was measured turbidimetrically.

\begin{tabular}{|c|c|c|c|c|}
\hline Carbon source & $\begin{array}{c}\text { Concn. } \\
\text { (M) }\end{array}$ & $\begin{array}{l}\text { Maximum yield } \\
\left(\times 10^{B} \text { organisms } / \mathrm{ml} .\right)\end{array}$ & $\begin{array}{l}\text { Time } \\
\text { required } \\
\text { (days) }\end{array}$ & $\begin{array}{c}\text { Mean } \\
\text { generatio } \\
\text { time (hr. }\end{array}$ \\
\hline D-Glucose & $\begin{array}{l}0 \cdot 1 \\
0 \cdot 05 \\
0 \cdot 025\end{array}$ & $\begin{array}{l}5 \cdot 8 \\
1 \cdot 1 \\
0 \cdot 1\end{array}$ & $\begin{array}{l}14 \\
16 \\
18\end{array}$ & $\begin{array}{c}42 \cdot 1 \\
63 \cdot 6 \\
-\end{array}$ \\
\hline D-Maltose & $\begin{array}{l}0 \cdot 1 \\
0 \cdot 05 \\
0 \cdot 025\end{array}$ & $\begin{array}{l}1 \cdot 0 \\
3 \cdot 7 \\
1 \cdot 6\end{array}$ & $\begin{array}{l}26 \\
28 \\
32\end{array}$ & $\begin{array}{r}132 \\
57 \cdot 6 \\
68 \cdot 7\end{array}$ \\
\hline D-Mannose & $\begin{array}{l}0 \cdot 1 \\
0 \cdot 05 \\
0 \cdot 025\end{array}$ & $\begin{array}{l}2 \cdot 4 \\
0 \cdot 8 \\
0 \cdot 3\end{array}$ & $\begin{array}{l}13 \\
13 \\
19\end{array}$ & $\begin{array}{r}51 \cdot 8 \\
63 \cdot 9 \\
155 \cdot 2\end{array}$ \\
\hline D-Lactose & $\begin{array}{l}0 \cdot 1 \\
0 \cdot 05 \\
0 \cdot 025\end{array}$ & $\begin{array}{l}0 \cdot 8 \\
1 \cdot 5 \\
1\end{array}$ & $\begin{array}{l}42 \\
46 \\
76\end{array}$ & - \\
\hline D-Ribose & $\begin{array}{l}0.1 \\
0.05 \\
0.025\end{array}$ & $\begin{array}{l}0 \cdot 2 \\
0 \cdot 8 \\
0 \cdot 5\end{array}$ & $\begin{array}{l}36 \\
27 \\
36\end{array}$ & $\begin{array}{c}132 \\
70 \\
86 \cdot 7\end{array}$ \\
\hline D-Fructose & $\begin{array}{l}0.1 \\
0.05 \\
0.025\end{array}$ & $\begin{array}{l}- \\
0 \cdot 9 \\
0 \cdot 3\end{array}$ & $\begin{array}{l}\overline{18} \\
22\end{array}$ & $\begin{array}{r}\overline{80.4} \\
101.4\end{array}$ \\
\hline D-Xylose & $\begin{array}{l}0 \cdot 1 \\
0 \cdot 05 \\
0 \cdot 025\end{array}$ & $\begin{array}{l}- \\
0 \cdot 7 \\
0 \cdot 5\end{array}$ & $\begin{array}{l}- \\
34 \\
41\end{array}$ & $\overline{-}$ \\
\hline D-Glucosamine $\mathbf{H C l}$ & $\begin{array}{l}0.1 \\
0.05 \\
0.025\end{array}$ & $\overline{-}$ & $\overline{-}$ & - \\
\hline D-Galactose & $\begin{array}{l}0.1 \\
0.05 \\
0.025\end{array}$ & $\begin{array}{l}- \\
0.2 \\
0.4\end{array}$ & $\begin{array}{l}\overline{27} \\
32\end{array}$ & $\begin{array}{l}\overline{151} \\
108.5\end{array}$ \\
\hline D-Lyxose & $\begin{array}{l}0.1 \\
0.05 \\
0.025\end{array}$ & $\overline{-}$ & $\frac{-}{38}$ & - \\
\hline L-Rhamnose & $\begin{array}{l}0.1 \\
0.05 \\
0.025\end{array}$ & $\begin{array}{l}-\overline{0.2} \\
0 \cdot 1\end{array}$ & $\begin{array}{l}-\overline{39} \\
45\end{array}$ & - \\
\hline
\end{tabular}

i-erythritol, D-sorbitol or dulcitol. Optimum growth with sodium acetate occurred at $\mathrm{pH} 6.5$ and 0.025 and $0.05 \mathrm{M}$, which coincides with the optimum pH value for growth with glucose.

Effect of Proteose peptone and yeast extract on growth. Concentrations of Proteose peptone greater than $1 \%$ (w/v) supported the growth of Hartmannella rhysodes in the absence of an added carbon source. At $2 \%(w / v)$ Proteose peptone, the maximum yield was less than $0.1 \times 10^{6}$ organisms $/ \mathrm{ml}$. No growth was detected by turbidimetry with $1 \%(w / v)$ Proteose peptone. Yeast extract was also capable of supporting very poor growth in the absence of an added carbon source. A maximum yield of less than $0.1 \times 10^{6}$ organisms $/ \mathrm{ml}$. was obtained with $0 \cdot 1 \%(\mathrm{w} / \mathrm{v})$ yeast extract. 
In Amoeba Medium containing 0.1 M-glucose, Proteose peptone and yeast extract affect the maximum yield of amoebae (Fig. 5), but did not alter the generation time. In the presence of $0.025 \mathrm{M}$-glucose, the generation time (and maximum yield) increased with increasing concentrations of yeast extract and Proteose peptone (Fig. 5).

Table 4. Growth of Hartmannella rhysodes with sodium acetate

Organisms were grown at $27^{\circ}$ on a shaker in Amoeba Medium containing sodium acetate as the carbon source. The pH was adjusted with known amounts of $\mathrm{HCl}$. Data are presented as the mean of duplicate cultures. Growth was measured turbidimetrically.

\begin{tabular}{|c|c|c|c|}
\hline & $\underset{\text { (initial) }}{\mathbf{p H}}$ & $\begin{array}{c}\text { Maximum yield } \\
\left(\times 10^{6} \text { organisms } / \mathrm{ml} .\right)\end{array}$ & $\begin{array}{l}\text { Time } \\
\text { required } \\
\text { (days) }\end{array}$ \\
\hline $0 \cdot 1 \mathrm{M}-\mathrm{NaAc}$ & $\begin{array}{l}5 \cdot 9 \\
6 \cdot 2 \\
6 \cdot 4 \\
6 \cdot 6\end{array}$ & $\begin{array}{l}\overline{-} \\
\overline{0.4} \\
0 \cdot 5\end{array}$ & $\begin{array}{l}\overline{-} \\
\overline{24} \cdot 5 \\
31\end{array}$ \\
\hline $0.05 \mathrm{M}-\mathrm{NaAc}$ & $\begin{array}{l}5 \cdot 8 \\
6 \cdot 1 \\
6 \cdot 3 \\
6 \cdot 6\end{array}$ & $\begin{array}{l}0 \cdot 4 \\
0 \cdot 4 \\
0 \cdot 3 \\
0 \cdot 4\end{array}$ & $\begin{array}{l}31 \\
28 \cdot 5 \\
26 \\
27\end{array}$ \\
\hline $0.025 \mathrm{M}-\mathrm{NaAc}$ & $\begin{array}{l}5 \cdot 7 \\
6 \cdot 0 \\
6 \cdot 2 \\
6 \cdot 5\end{array}$ & $\begin{array}{l}0 \cdot 4 \\
0 \cdot 3 \\
0 \cdot 3 \\
0 \cdot 5\end{array}$ & $\begin{array}{l}27 \\
28 \\
23 \cdot 5 \\
23\end{array}$ \\
\hline $0 \cdot 05$ M-Glucose & $\begin{array}{l}5 \cdot 4 \\
5 \cdot 9 \\
6 \cdot 1 \\
6 \cdot 5\end{array}$ & $\begin{array}{l}2 \cdot 3 \\
1 \cdot 9 \\
1 \cdot 9 \\
2 \cdot 3\end{array}$ & $\begin{array}{l}32 \cdot 5 \\
28 \\
23 \\
23\end{array}$ \\
\hline
\end{tabular}

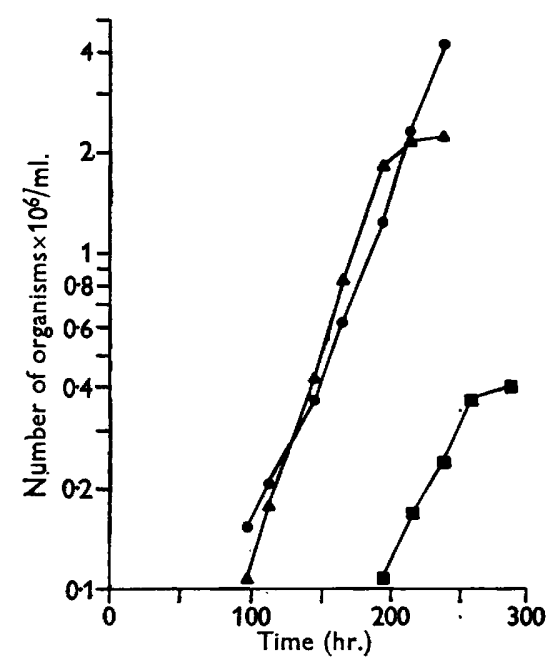

Fig. 3

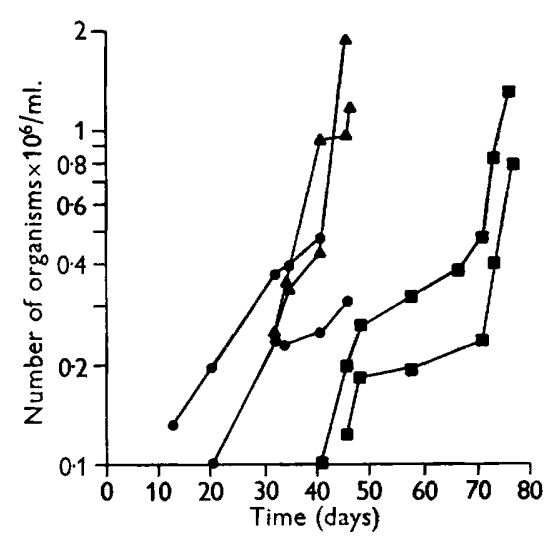

Fig. 4

Fig. 3. Growth with glucose at $30^{\circ}$ on a shaker. Each point represents the mean of duplicate cultures with glucose concentrations of $0.1 \mathrm{M}(0), 0.05 \mathrm{M}(\Delta)$ and $0.025 \mathrm{M}(\square)$.

Fig. 4. Growth with lactose at $27^{\circ}$ on a shaker. $\bullet, 0.1 \mathrm{M} ; \Delta, 0.05 \mathrm{M} ; \boldsymbol{\square}, 0.025 \mathrm{M}$. 
Growth response of Acanthamoeba castellanii to glucose. The growth response of $A$. castellanii to different glucose concentrations in Amoeba Medium was tested at $30^{\circ}$ in stationary cultures. The results (Table 5) indicate that $A$. castellanii responded to different glucose concentrations in a manner similar to Hartmannella rhysodes. The organism differed from $H$. rhysodes in exhibiting slight growth (approximately $0.1 \times 10^{6}$ organisms $/ \mathrm{ml}$.) in the presence of $1 \%(w / v)$ Proteose peptone without an added carbon source.

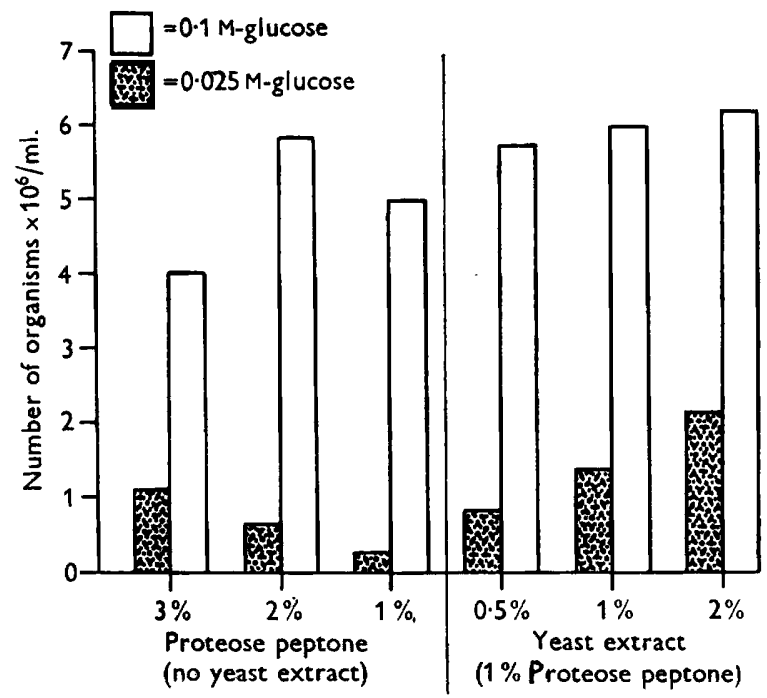

Fig. 5. Effect of Proteose peptone and yeast extract on growth in the presence of glucose. Shown as the average maximum yields of duplicate cultures.

Table 5. Growth of Acanthamoeba castellanii with glucose

Organisms were grown at $30^{\circ}$ in static cultures of Amoeba Medium. Growth was measured turbidimetrically.

$\begin{array}{ccc}\begin{array}{c}\text { Glucose } \\ \text { concn. } \\ \text { (M) }\end{array} & \begin{array}{c}\text { Maximum yield } \\ \left(\times 10^{6} \text { organisms } / \text { ml. }\right)\end{array} & \begin{array}{c}\text { Time } \\ \text { required } \\ \text { (days) }\end{array} \\ 0.1 & 0.91 & 27 \\ & 0.52 & 24 \\ 0.05 & 0.43 & 12 \\ & 0.43 & 18 \\ 0.025 & \text { Less than } 0.1 & 12 \\ & 0.155 & 16\end{array}$

\section{Utilization of glucose}

Direct demonstration of glucose utilization after growth. Analysis of Hartmannella rhysodes cultures by the Nelson modification of the Somogyi test for reducing sugars did not reveal any significant change in reducing sugar concentration after growth in Amoeba Medium. The results of an analysis of duplicate cultures after exponential growth, by the glucose oxidase test and the anthone test for reducing sugars, are given in Table 6 as the mean of 
duplicate determinations and in Fig. 6 as percentage of the glucose initially present. The results indicate that glucose was used during growth, but a reducing substance was produced which reacted with the anthrone.

Direct demonstration of glucose utilization by resting organisms. The organisms (45 to $50 \times 10^{6} / \mathrm{ml}$.) were placed in $50 \mathrm{ml}$. silicone-coated Erlenmeyer flasks with $5 \mathrm{ml}$. test solution. The test solutions were composed of $5 \cdot 8 \mathrm{~g} . \mathrm{NaCl} ; 3 \mathrm{mg}$. $\mathrm{MgCl} .6 \mathrm{H}_{2} \mathrm{O} ; 3 \mathrm{mg} . \mathrm{CaCl}_{2} ; 3 \mathrm{mg}$. $\mathrm{FeSO}_{4} ; 142 \mathrm{mg} . \mathrm{Na}_{2} \mathrm{HPO}_{4} ; 136 \mathrm{mg} . \mathrm{KH}_{2} \mathrm{PO}_{4} ;$

Table 6. Sugar analysis with glucose oxidase and anthrone of Hartmannella rhysodes cultures after exponential growth

Specific determination of glucose was accomplished with glucose oxidase ('Glucostat'). Anthrone was used as a test for reducing sugars.

\begin{tabular}{|c|c|c|c|c|}
\hline \multirow[b]{2}{*}{$\begin{array}{c}\text { Original } \\
\text { concn. } \\
(\mathrm{mg} \cdot / \mathrm{ml} .)\end{array}$} & \multicolumn{2}{|c|}{ Amount of glucose used (mg./ml.) } & \multirow[b]{2}{*}{$\begin{array}{c}\text { Incubation } \\
\text { time } \\
\text { (days) }\end{array}$} & \multirow[b]{2}{*}{$\begin{array}{c}\text { Maximum yield } \\
\left(\times 10^{6} \text { organisms } / \mathrm{ml} .\right)\end{array}$} \\
\hline & $\begin{array}{l}\text { Glucose } \\
\text { oxidase }\end{array}$ & Anthrone & & \\
\hline 27 & $\mathbf{3} \cdot \mathbf{3}$ & $3 \cdot 36$ incr. & 10 & $\mathbf{5 \cdot 4}$ \\
\hline 18 & 4.5 & 0.2 incr. & 11 & $\mathbf{2} \cdot \mathbf{1}$ \\
\hline 9 & $4 \cdot 04$ & $0 \cdot 7$ & 11 & $\mathbf{2} \cdot \mathbf{1}$ \\
\hline $4 \cdot 5$ & $1 \cdot 58$ & $1 \cdot 1$ & 13 & $0 \cdot 6$ \\
\hline
\end{tabular}

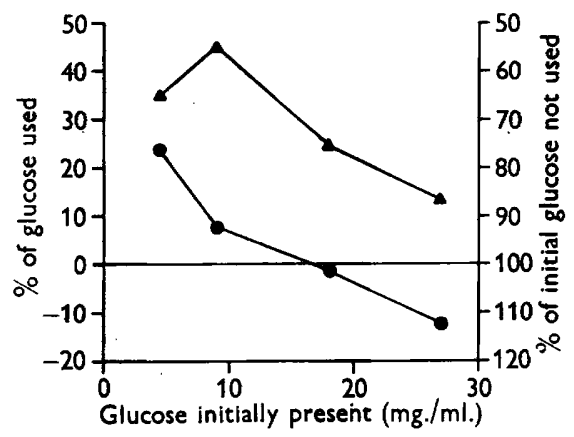

Fig. 6

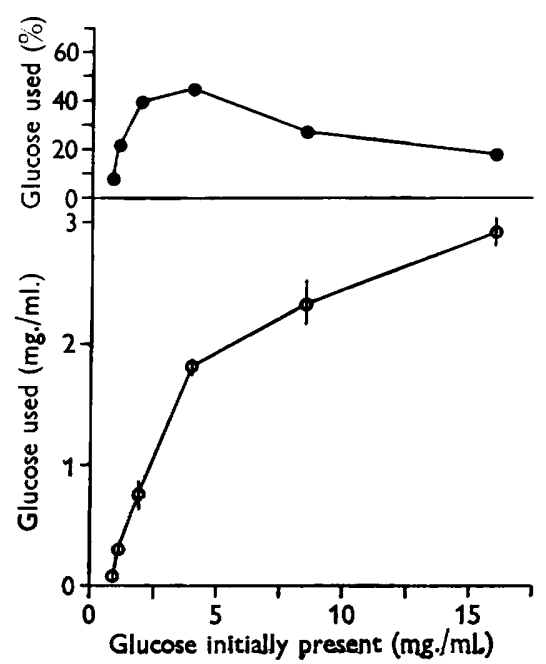

Fig. 7

Fig. 6. Percentage of initial concentration of glucose used after exponential growth, determined by glucose oxidase $(\Delta)$ and anthrone $(O)$.

Fig. 7. Uptake of glucose by $50 \times 10^{6}$ resting organisms $/ \mathrm{ml}$. after a $24 \mathrm{hr}$. period. At each concentration four suspensions were tested with glucose oxidase; the results given as the mean and range of these determinations.

water to 11 .; this will be designated as Amoeba Saline. To the Amoeba Saline were added different concentrations of glucose. The results of uptake of glucose by resting organisms as determined by the glucose oxidase test are plotted in Fig. 7. All experiments were done in quadruplicate for 
a $24 \mathrm{hr}$. period. Anthrone determinations after $24 \mathrm{hr}$. indicated an approximate doubling of the reducing sugar concentrations. The medium became alkaline $(\mathrm{pH} \mathrm{8 \cdot 0-8 \cdot 2)}$ in all cases. Counts before and after experiments indicated that no appreciable cytolysis of organisms took place. Cysts were not observed after incubation for $24 \mathrm{hr}$.

Distribution of uniformly labelled glucose ${ }^{14} \mathrm{C}$. Amoebae were grown for 5 days in $10 \mathrm{ml}$. Amoeba Medium with labelled 0.1 M-glucose having a specific activity of 442.5 counts $/ \mathrm{min} . / \mathrm{mg}$. carbon. During growth all of the $\mathrm{CO}_{2}$ was collected. After growth the medium was acidified (pH 5) with $\mathrm{KH}_{2} \mathrm{PO}_{4}$, and the residual $\mathrm{CO}_{2}$ was collected. The amoebae were then harvested, washed in Amoeba Saline, suspended in $1 \mathrm{ml}$. Amoeba Saline and returned to the $50 \mathrm{ml}$. incubation flask for $24 \mathrm{hr}$. All of the $\mathrm{CO}_{2}$ was collected from the resting organisms. Dry weights of organisms were determined before and after starvation. Glucose concentrations of culture medium before and after growth, and of Amoeba Saline, were determined by the glucose oxidase test.

Of the glucose used, $24 \cdot 1 \%$ was assimilated, $40 \%$ was returned to the medium as compounds other than glucose and $52 \cdot 8 \%$ was converted to $\mathrm{CO}_{2}$. The error in ${ }^{14} \mathrm{C}$ recovery $(5 \%)$ and the error in the glucose determinations $(11.9 \%)$, before and after growth, account for a total in excess of $100 \%$. Assimilated carbon from glucose contributed $21.1 \%$ of the total carbon in the amoebae. Glucose carbon contributed to $76 \cdot 4 \%$ of the total $\mathrm{CO}_{2}$ produced. After starvation for $24 \mathrm{hr}$, the amoebae lost $\mathbf{5 7 . 7 \%}$ of their dry weight, which included $6.95 \%$ of carbon derived from glucose lost to the medium and $29 \cdot 4 \%$ lost to the $\mathrm{CO}_{2}$. Of the glucose carbon returned to the Amoeba Saline, $54 \%$ was glucose. The specific activity of the amoeba carbon increased from 93.5 to 111 counts/min./mg. carbon.

Weights of cell fractions. In order to characterize partially the chemical components of the organism which contributed to the endogenous respiration, organisms were fractionated and weighed. Fresh and starved organisms were washed in saline and distilled water in weighed centrifuge tubes, dried over $\mathrm{P}_{2} \mathrm{O}_{5}$ and weighed. The organisms were then extracted twice for $20 \mathrm{~min}$. with 2 vol. of cold $5 \%(w / v)$ trichloroacetic acid (TCA), followed by a wash with 1 vol. of cold $1 \%(\mathrm{w} / \mathrm{v})$ TCA. The precipitate was dried over $\mathrm{P}_{2} \mathrm{O}_{5}$ and weighed. It was then extracted with $50 \mathrm{vol}$. of ethanol + ether $(3: 1, \mathrm{v} / \mathrm{v})$ in three batches, dried over $\mathrm{P}_{2} \mathrm{O}_{5}$ and weighed. The results, presented in Table 7 , indicate that the TCA-soluble fraction was responsible for most of the loss of dry weight from starved cells.

Carbon, hydrogen, oxygen and nitrogen determinations. The carbon, hydrogen, oxygen and nitrogen contents of fresh and starved organisms were determined by the direct analysis of all components except oxygen, whose content was calculated after correction for ash weight. The results are presented in Table 8.

Production of reducing compounds. A reducing substance which reacts with anthrone has already been described above for cultures containing glucose, as well as for resting organisms in the presence of glucose. Reducing compounds were also produced by cultures in which sodium acetate or glycerol served as added carbon sources; other added carbon sources were not investigated. 
Organisms were harvested, washed and starved in Amoeba Saline under shaking conditions for $72 \mathrm{hr}$. Every $24 \mathrm{hr}$. they were transferred to fresh saline. After $24 \mathrm{hr}$. cytolysis began to become noticeable, so that at the end of the $72 \mathrm{hr}$. period, one-half of the original number was present (20 to $25 \times 10^{6} \mathrm{organisms} / \mathrm{ml}$.). The Molisch reaction of equal intensity was obtained with samples of cell-free saline taken after all three time periods. There was no reaction with anthrone after the first $24 \mathrm{hr}$. period.

After $24 \mathrm{hr}$. of starvation, 45 to $50 \times 10^{6}$ organisms $/ \mathrm{ml}$. were incubated with $0 \cdot 1 \mathrm{~m}$-glucose with $20,10,5$ and $0 \mathrm{mg} . / \mathrm{ml}$. Proteose Peptone. Analysis by glucose oxidase and anthrone failed to reveal any effect of Proteose Peptone on glucose uptake or on the production of reducing compounds.

\section{Table 7. Dry weights of cell fractions}

Precipitate dried over $\mathrm{P}_{2} \mathrm{O}_{5}$. Soluble fraction calculated from the loss of dry weight. Cells starved for $24 \mathrm{hr}$.

$\begin{array}{lcc} & \begin{array}{c}\text { Fresh } \\ \text { organisms, } \\ \% \text { total } \\ \text { weight }\end{array} & \begin{array}{c}\text { Starved } \\ \text { organisms, } \\ \text { \% total } \\ \text { weight }\end{array} \\ \text { TCA soluble } & 53 & 44 \\ \text { TCA precipitate } & \mathbf{4 7} & \mathbf{5 6} \\ \text { Alcohol +ether soluble } & \mathbf{2 4} & \mathbf{2 3 \cdot 8} \\ \text { Extracted precipitate } & \mathbf{2 2 \cdot 6} & \mathbf{3 2}\end{array}$

Table 8. Carbon, hydrogen, oxygen and nitrogen content of Hartmannella rhysodes

Total nitrogen determined by Kjeldahl method; total carbon-hydrogen determined by combustion; total oxygen calculated by difference after correction for ash weight.

$\begin{array}{lllll} & \% \mathrm{C} & \% \mathrm{H} & \% \mathrm{O} & \% \mathrm{~N} \\ \text { Fresh organisms } & \mathbf{4 6 \cdot 9} & \mathbf{7 \cdot 4 1} & \mathbf{3 0 \cdot 3} & 10 \\ \text { Starved organisms } & \mathbf{4 7 \cdot 2} & \mathbf{7 \cdot 1 5} & \mathbf{2 9 \cdot 2} & \mathbf{1 0 \cdot 2 5}\end{array}$

\section{DISCUSSION}

Carbon sources

Utilization of known carbon sources. The only investigators who have used quantitative methods for describing the suitability of various carbon sources to support the growth of soil amoebae are Neff et al. (1958). Their data are presented in terms of yield, without regard to generation time, from cultures harvested after 2 weeks of incubation. Under these conditions there is no criterion by which to assume that the cultures were harvested at maximum growth. Neff et al. (1958) autoclaved all of the sugars in the presence of medium at an acid $\mathrm{pH}$ value. Although all the products of this operation are not predictable, there is no doubt that sugars are not stable (Davis \& Rogers, 1939). Both Hartmannella rhysodes (from the results presented here) and Neff's Acanthamoeba sp. (Neff et al. 1958) use glucose, maltose, mannose, lactose, ribose, fructose, and galactose, neither uses arabinose, dulcitol and sorbitol. Only $\boldsymbol{H}$. rhysodes uses xylose and rhamnose. Only Acanthamoeba sp. 
(Neff et al. 1958) uses sucrose and raffinose. It would be interesting to see whether unautoclaved sucrose supports the growth of Acanthamoeba sp. since $H$. rhysodes can grow with sucrose as carbon source when the medium containing sucrose is autoclaved. Glucose, maltose and mannose support the best growth of $\boldsymbol{H}$. rhysodes.

Neff et al. (1958) found optimal growth in $0.05 \mathrm{M}$-sodium acetate at $\mathrm{pH} 6$, whereas in glucose the optimum was pH 5.6. Cultures of a 'given series' were harvested at the same time. If this means all acetate cultures were harvested at one time, and that all glucose cultures were harvested at one time, then there is no criterion for assuming that their results are based on maximum yields. Hartmannella rhysodes grows best with 0.025 and $0.05 \mathrm{M}$-sodium acetate at $\mathrm{pH} 6.5$, which coincides with the optimum $\mathrm{pH}$ value for growth with glucose.

The irregular growth obtained in lactose (Fig. 4) is similar to a diauxic growth curve. If this is true, then lactose is probably broken down to glucose and galactose, one is used and after a lag phase the other is used.

Role of Proteose peptone and yeast extract. The results presented here demonstrate that Proteose peptone and yeast extract served as carbon sources for Hartmannella rhysodes (Fig. 5), and Proteose peptone (yeast extract not tested) in the case of Acanthamoeba castellanii (Table 5). The experiment with uniformly labelled ${ }^{14} \mathrm{C}$ glucose indicates that Proteose peptone carbon contributed $24 \%$ of the $\mathrm{CO}_{2}$ produced by the amoebae and $79 \%$ of the assimilated carbon. These results may be used as a possible explanation of Cailleau's $(1933 a, b)$ finding that Acanthamoeba castellanii grew in a minimum of $3 \%$ peptone and that added sugars had no effect on growth. Although no data are available, the carbon content of the $3 \%$ peptone used by Cailleau was undoubtedly higher than that of $1 \%$ Proteose peptone. Since Cailleau's cultures were limited by the concentration of peptone, the limiting factor or factors may have served some function other than that of a carbon source. Under these conditions, added carbon sources might not have any noticeable effect on growth.

The shift to an alkaline $\mathrm{pH}$ value and the failure of other workers (Cailleau, $1933 b$; Neff $e t$ al. 1958) to demonstrate the disappearance of sugars from media after growth has led to the speculation by others that nitrogenous compounds serve as a primary carbon source of these small soil amoebae. However, in view of the observations presented here, as well as the fact that peptone digests contain more than just nitrogen compounds, it does not seem likely that nitrogenous compounds are used preferentially as a carbon source.

Utilization of glucose. There has been no direct evidence of carbohydrate utilization in small soil amoebae. Reich (1948) was unable to demonstrate any effect of glucose on the respiration of Mayorella palestinensis in washed suspensions; Neff et al. (1958) have also found this with Acanthamoeba sp. In both cases, however, glucose or some other added carbon source in addition to Proteose Peptone was required for growth. From the fractionation studies presented here on fresh and starved organisms (Table 7), the TCA-soluble fraction appears to be the main site of endogenous respiration. The increase in specific activity of the total carbon of the organism after endogenous respira- 
tion indicates that more of the organism's components derived from carbon sources other than glucose are lost than those derived from glucose.

Cailleau $(1933 b)$ was unable to demonstrate any change in reducing sugar content when glucose was added to cultures of Acanthamoeba castellanii. Neff et al. (1958) were also unable to demonstrate a decrease in reducing sugar content of medium, in spite of the fact that Acanthamoeba sp. requires it for growth in the presence of $1 \%$ Proteose Peptone. Neff et al. (1958) were able to demonstrate a decrease in the reducing content of culture medium after 35 weeks of incubation. They were also able to demonstrate after 3 days of incubation a $35 \%$ decrease in reducing value of a washed suspension containing approximately twice the maximum yield of organisms and $0.05 \mathrm{M}$-glucose. From their respirometry and resting-cell data, it can be calculated that less than $1 \%$ of the $\mathrm{CO}_{2}$ would come from the added carbon source, if all of it were used for respiration.

The data presented here on the changes in reducing-sugar concentration and glucose concentration of culture media (Table 6, Fig. 6) indicate that Neff et al. (1958), by determining glucose concentrations with a reducing sugar test, did not measure the disappearance of glucose but rather the total reducingsugar content of the medium. It is possible to demonstrate (Table 6, Fig. 6) that culture media containing suboptimal amounts of glucose show a moderate decrease in reducing sugars after growth. The specific analysis for glucose in parallel with reducing-sugar determinations (Table 6, Fig. 6) demonstrates that glucose is used in appreciable quantity. The labelled glucose experiment demonstrates that glucose is utilized as a carbon source for energy and assimilation. It is also of interest to note from this experiment that a large portion of the glucose is returned to the medium in an altered form.

Diffusion barrier. The requirement for large amounts of glucose in proportion to the amount used by growing organisms suggests a diffusion problem. The amount of glucose used by washed organisms (Fig. 7) is proportional to the concentration in the range in which the mean generation time of growing organisms is similar. This suggests that if glucose is transported actively into the cell, the carrier is not yet saturated and that passage is still dependent on the external concentration of glucose. An alternative would be that glucose uptake is accomplished by diffusion.

The possibility of a diffusion problem is also supported by the observation that there is no optimal osmotic concentration at the concentrations tested (Fig. 2). Since the concentrations tested fell within the range of optimal growth, it may be assumed that osmotic concentrations necessary for optimal growth are above the real optimal osmotic concentration. If this be true, then the amoeba has adapted itself to living in environments of high osmotic concentration by forming a diffusion barrier. In its natural environment this barrier would not present any difficulties since it would be feeding on particulate matter such as bacteria. Furthermore, although the amoebae are found in soil and environments of high osmotic pressure such as faeces and sewage, it is possible that a satisfactory natural environment might be fresh water.

The mean generation time for Hartmannella rhysodes under optimal 
conditions was $26 \mathrm{hr}$. This is similar to the minimum mean generation time for Acanthamoeba sp. (Neff et al. 1958). In comparison to other protozoa, the mean generation times for these amoebae are exceptionally long. This may mean that the experimental conditions for the cultivation of these amoebae were not optimal, or that this is one of the inherent properties of the small soil amoebae. Although no quantitative data are available the mean generation times of these amoebae appear to be much shorter in the presence of bacteria (and a lower osmotic pressure). It would thus appear that the media used for the cultivation of these amoebae under axenic conditions was not optimal.

\section{Oxygen requirement and the influence of surfaces}

Aeration. The results indicate that Hartmannella rhysodes is an obligate aerobe. Attempts by others to aerate cultures of hartmannellids have yielded confusing results. According to Storm, Hutner \& Cowperthwaite (1951), H. rhysodes and Acanthamoeba castellanii are indifferent to aeration. Neff et al. (1958) found that aeration by swirling suppressed growth as compared to equivalent static cultures of Acanthamoeba sp. However, Neff et al. (1958) found that shallow cultures supported better growth than deep cultures and that aeration by bubbling supported the best growth.

If organisms which adhere to the glass surface of culture vessels are ruptured when the vessel is swirled, then the results quoted above can be explained on the basis of surface sensitivity. Neff et al. (1958) used silicone grease to prevent the organisms from sticking to glass surfaces in vessels used for direct counts, but did not coat growth vessels. The method of aeration used by Storm, Hutner \& Cowperthwaite (1951) was not mentioned.

Cysts have never been seen in deep standing cultures, whereas in equally deep agitated cultures or in shallow standing cultures, cysts were formed. In all cases round forms were seen, identical with those described by Ray \& Hayes (1954) as precystic amoebae. Since the only variable is the degree of aeration, it would seem that a final step in encystation requires optimal aeration.

Effect of agents to increase viscosity. Balamuth (1957) reports that silica gel or agar improved the growth of Entamoeba invadens, and that this action was independent of the reducing condition of the medium. No evidence was found by me, that addition of sodium carboxymethyl cellulose to increase the viscosity was beneficial to the growth of Hartmannella rhysodes. If it be assumed that the results reported here indicate that amoebae do not require a surface for growth, then any benefit derived from the addition of an agent to increase viscosity might be due to the creation of more surfaces for the amoebae to distribute themselves in the absence of agitation.

This study is part of a dissertation submitted in partial fulfilment of the requirements for the degree of Doctor of Philosophy in Zoology at the University of California, and was conducted under the direction of Professor William Balamuth. Grateful acknowledgement is hereby extended also to Professor Michael Doudoroff and to Professor Morgan Harris for advice and material support given during the course of the investigation. The last year of study was greatly aided by award of a U.S. Public Health Service Predoctoral Fellowship of the National Institutes of Health. 


\section{REFERENCES}

Balamuth, W. (1957). Concerning the role of oxidation-reduction potentials in encystation of parasitic amoebae. J. Protozool. 4 (suppl.), 15.

Cailleau, R. (1933a). Culture d'Acanthamoeba castellanii en milieu liquide. C.R. Soc. Biol., Paris, 113, 990.

Cailleau, R. (1933b). Culture d'Acanthamoeba castellanii sur milieu peptoné. Action sur les glucides. C.R. Soc. Biol., Paris, 114, 474.

Carlleau, R. (1934). Utilisation des milieux liquides par Acanthamoeba castellanii. C.R. Soc. Biol., Paris, 116, 721.

Davis, J. G. \& Rogers, H. J. (1939). The effect of sterilization upon sugars. Zbl. Bakt. (Abt. 11) 101, 102.

Gortner, R. A. \& Harris, J. A. (1914). Notes on the technique of the determination of the depression of the freezing point of vegetable saps. Plant World, 17, 49.

Nefr, R. J. (1957). Purification, axenic cultivation, and description of a soil amoeba, Acanthamoeba sp. J. Protozool. 4, 176.

NefF, R. J., NefF, R. H. \& TAYLOR, R. E. (1958). The nutrition and metabolism of a soil amoeba, Acanthamoeba sp. Physiol. Zoöl. 31, 73.

Nelson, N. (1944). A photometric adaptation of the Somogyi method for the determination of glucose. J. biol. Chem. 153, 375 .

Oenler, R. (1916). Amöbenzucht auf reinem Boden. Arch. Protistenk. 37, 175.

Oenler, R. (1924). Weitere Mitteilungen über gereinigte Amöben- und Ciliatenzucht. Arch. Protistenk. 49, 112.

RAY, D. L. \& Hayes, R. E. (1954). Hartmannella astronyxis; a new species of freeliving ameba. Cytology and life cycle. J. Morph. 95, 159.

REICH, K. (1935). The cultivation of a sterile amoeba on media without solid food. J. exp. Zool. 69, 497.

REICH, K. (1948). Studies on the respiration of an amoeba, Mayorella palestinensis. Physiol. Zoöl. 21, 390.

REICH, K. (1955). The effect of cyanide and axide on the respiration of the amoeba Mayorella palestinensis. Physiol. Zoöl. 28, 145.

Singh, B. N. (1952). Nuclear division in nine species of small free-living amoebae and its bearing on the classification of the order Amoebida. Phil. Trans. B, 236, 405.

Steyermark, A. (1951). Quantitative Organic Microanalysis. New York: Blakiston Co.

Storm, J., Hutner, S. H. \& Cowperthwaite, J. (1951). Preliminary notes on the nutrition of two small amoebae in pure culture. Proc. Amer. Soc. Protozool. 2, 3.

Sübhof, H., Kellner, H. \& Schulte, N. (1955a). Über den Eiweisszucker. 1. Mitteil.: Kritische Betrachtungen der kolorimetrischen Kohlenhydratbestimmungs-methoden. Hoppe-Seyl. Z. 300, 68.

Sübhof, H., Kellner, H. \& Schulte, N. (1955b). 2. Mitteil.: Zur Bestimmung im Serum. Hinweise auf unterschiedliche Stabilität des Eiweiss-KohlenhydratKomplexes. Hoppe-Seyl. Z. 300, 82.

(Received 1 December 1958) 